\title{
The Influence of Organizational Boundary Flexibility on Enterprise Innovation Performance
}

\author{
Jiahui Wang* \\ International Business School \\ Tianjin University of Finance and Economics \\ Tianjin, China \\ 13223286657@163.com
}

\author{
Huimei Jiang \\ International Business School \\ Tianjin University of Finance and Economics \\ Tianjin, China
}

\author{
Tong Ye \\ International Business School \\ Tianjin University of Finance and Economics \\ Tianjin, China
}

\begin{abstract}
From the perspective of management, this paper studies the linkage mechanism between organizational boundary flexibility and innovation performance, and establishes the correlation model with innovation capability as the intermediary variable. We performed exploratory factor analysis on the data, established the structural equation model, performed confirmatory factor analysis on the measurement model, and finally verified the intermediate effect by bootstrap. Among them, network capability and IT capability have a direct positive impact on innovation performance, which are 0.301 and 0.357 respectively. This study expands the theoretical research scope of enterprise organizational boundary flexibility and innovation performance. It provides practical guidance for Chinese enterprises to improve innovation performance through reasonable organizational boundary flexibility.
\end{abstract}

Keywords-organizational boundary; innovation performance; innovation ability; bootstrap method

\section{INTRODUCTION}

Under the background of globalization, how to improve innovation capability and promote innovation performance by adjusting the flexibility of organizational boundaries has become an important challenge for Chinese enterprises.

Research by Liu and others [1] shows that IT capability; network capability and absorptive capability can be used to quantify organizational boundaries. This paper reviews the theories of organizational boundaries, IT capabilities, network capabilities, absorptive capabilities, innovation capabilities and innovation performance. By introducing intermediary variables of innovation capabilities, it is assumed that IT capabilities, network capabilities and absorptive capabilities can have a positive impact on innovation performance through the intermediary variables of innovation capabilities. The model is validated by 223 questionnaires collected successfully, and its theoretical and practical significance is discussed.

\section{THEORETICAL RESEARCH AND HYPOTHESIS PRESENTATION}

\section{A. Theoretical review}

1) Overview of research on organizational boundaries

Boundaries exist in all organizations. Bruce et. al [2] believe that the core competitiveness of enterprises in the same industry is how to effectively create and transfer knowledge in the organizational environment. Liu et. Al [3] believe that comprehensive consideration of the expansion of research and development network organizational boundary, geographical boundary and knowledge boundary is conducive to improving enterprise innovation performance. Existing literature on enterprise network capacity focuses more on the evolution of organizational boundary expansion.

2) Organizational boundary crossing and organizational boundary flexibility

Andersen et. al [4] believe that the purpose of boundary crossing activities is to integrate knowledge across boundaries, and effective boundary crossing can help the organization integrate innovation input inside and outside. Organizational cross boundary behavior can include learning across organizational boundaries [5]. Organizational cross-border capability can be analyzed from the aspects of boundary crossers, boundary crossing carriers and boundary crossing dynamics [6]. Based on the theory of enterprise capability, the problem of enterprise boundary is essentially the problem of the scope of enterprise capability [7]. Therefore, this paper measures the flexibility of organizational boundaries by the ability to cross organizational boundaries.

\section{B. Conceptual models and research hypotheses}

This paper summarizes and collates the previous research results, using organizational boundary crossing ability to measure organizational boundary flexibility, using absorptive capacity, network capacity and IT capacity to measure organizational boundary crossing ability. This paper constructs a conceptual model with innovation capability as a mediating variable to illustrate how organizational boundary flexibility affects enterprise innovation performance. 
1) The relationship between organizational boundary flexibility and innovation capability

Through the evaluation index system of enterprise performance promotion based on network capability, Li et al. [8] draw the conclusion that network capability has a positive impact on enterprise innovation capability promotion, and then promote enterprise innovation performance improvement. Chang et. al [9] believe that the establishment of stable and close network relationship between enterprises is conducive to the development of enterprises' innovation ability and thus enhance the innovation performance of enterprises. Based on previous conclusions, the following assumptions will be made:

H1: Network capability is positively related to enterprise innovation capability.

Integrating the past failures of enterprises in using IT for innovative management, the academic world put forward the concept of 'IT capability'. It is thought that IT capabilities can be determined by a wide variety of factors, such as IT infrastructure, IT related costs, IT intangible assets, etc. By improving the IT capability of enterprises, it is of great importance to improve the innovation capability of enterprises [10]. At present, there are few studies on the impact of IT capability on enterprise innovation capability. Zheng et al. hold that IT capability can only be improved through the intermediary role of knowledge sharing [11]. Chen et al. summarized IT capability as IT business application level and IT collaborative integration level, which indirectly showed that IT capability can effectively enhance enterprise innovation capability [12]. Based on a large number of previous conclusions, the following assumptions are made:

H2: IT capability is positively related to enterprise innovation capability.

Through empirical analysis, Sun et al. proved that absorptive capacity is the foundation of enterprise innovation, which is helpful for enterprises to find and utilize more valuable resources from outside, and to internalize external resources rationally and efficiently, so as to improve enterprise innovation capability [13]. Zhang believes that for enterprises, the improvement of absorptive capacity benefits from the absorption of knowledge from the outside and the digestion, absorption, transformation and application of knowledge, which is conducive to the promotion of enterprise innovation capability [14]. Based on previous theories, this paper argues that absorptive capacity plays an indirect role in enterprise innovation performance through innovation capability, and puts forward the following assumptions:

H3: Absorptive capacity is positively related to enterprise innovation capability.

2) The influence of organizational boundary flexibility on enterprise innovation performance

As the environmental characteristics of enterprise innovation, the formation, structure, governance and evolution of network will affect enterprise innovation performance and competition situation. For example, Zhang pointed out that network capacity, as an enterprise's ability or skill to acquire various resources through building external relations, will have an impact on its performance (including innovation performance) [15]. Chen pointed out that for large high-tech enterprises, network scale and network scope have a significant positive impact on technological innovation performance, and organizational learning has a positive effect on the improvement of network capacity [16]. To sum up, we put forward the following assumption:

H4: Network capability has direct positive impact on enterprise innovation performance.

Enterprise innovation is based on the absorption of knowledge [17]. The enterprise's ability to absorb knowledge is the source of innovation and has an important influence on the enterprise's innovation ability and innovation performance [18] For example, Fabrizio pointed out that the more R\&D investment, the more patents available to pharmaceutical and biotechnology companies with broader links to universities, could be seen as the contribution of absorptive capacity to innovation activities [19]. Zhang pointed out that the absorptive capacity is influenced by the prior knowledge, research and development investment, staff training and institutional support and other factors, and the potential absorptive capacity and the realization of absorptive capacity are positively correlated with the enterprise innovation performance [20]. To sum up, we put forward the following assumption:

H5: Absorptive capacity has direct positive impact on enterprise innovation performance.

The stronger the IT capability of an enterprise, the higher the level of innovation should be. IT capabilities play an important role in building innovation platforms. For enterprises, innovation platform is a way to learn external knowledge and skills. In the case study of Haier Information System, Ouyang pointed out that the introduction and application of information system promoted the continuous expansion and crossing of organizational boundaries. $\mathrm{Li}$ et al. pointed out that IT can enhance the core competitiveness of enterprises. For example, The SABRE system not only gives American Airlines a direct strategic advantage, but also dramatically changes the industrial structure by creating conversion costs among scheduled agents [21]. In conclusion, IT capability has obvious positive effects on enterprise innovation. Therefore, we put forward the following assumption:

H6: IT capability has a direct positive impact on enterprise innovation performance.

\section{RESEARCH OBJECT AND MEASUREMENT:}

\section{A. presentation and measurement of variables}

IT capability is composed of IT construction, IT governance and IT application, and six measurement questions are designed. Drawing on the scale applied by Liu et al., the network capacity was divided into four aspects, namely, coordination activities, relationship skills, knowledge of partners and internal communication, with a total of six items. Drawing on the scale applied by Liu et al., the absorptive capacity was divided into four aspects: acquisition, digestion, transformation and utilization, with a total of 14 items. The innovation ability is divided into five items and measured. Innovation performance is measured by the number of patents granted each year. 


\section{B. The research assessment}

This paper adopts the method of questionnaire survey, from 2018-7-1 to 2018-7-26, sending 225 copies of the questionnaire and recovering 223 copies of the valid questionnaire, with an effective rate of $99 \%$.

\section{ANALYSIS OF RESULT}

\section{A. Analysis of reliability and validity}

SPSS 20 was used to test the reliability and validity of the recovered questionnaires. First, this paper use Cronbach $\propto$ coefficient to measure the inherent reliability of questionnaire, the questionnaire after the standardized Cronbach $\propto 0.854>$ 0.7 , think questionnaire has good reliability. Moreover, after each item delete Cronbach $\propto$ coefficient up to 0.943 , the minimum was 0.936 and the overall Cronbach $\propto$ coefficient were similar, so choose not to modify for item. Secondly, for the validity test of the scale, $\mathrm{KMO}=0.915$ and Bartlett sig value $=0.000$, which is suitable for factorial analysis. In this paper, principal component analysis was used to test the scale's structural validity. The classification of variables of each scale was consistent with the variable classification of the questionnaire. The factor loading was 0.677 . The validity of the scale was tested by principal component analysis. The classification of variables in each scale was consistent with the classification of variables in the questionnaire, and the factor loading was 0.677 , which verified that the scale had good structural validity.

\section{B. measurement model test}

Software AOMS24.0 was used to test the fitting quality of the single factor measurement model. Confirmatory factor analysis for innovation ability and absorption ability. For the fitting quality test of the innovation ability measurement model, the results are: $\mathrm{CMIN} / \mathrm{DF}=3.72<5 \mathrm{P}=0.024<0.05$, GFI $=0.983295417>0.9, \quad$ AGFI $=0.916477084>0.9$, $\mathrm{CFI}=0.963>0.9, \quad \mathrm{RMR}=0.037<0.05$, (AIC hypothesis model $=23.486)<($ AIC independent model 165.534). The results all met the requirements of the judgment standard

The test result of the absorption capacity measurement model is $\mathrm{CMIN} / \mathrm{DF}<5 \quad \mathrm{CMIN}=12.73, \mathrm{P}=0.000, \quad \mathrm{GFI}=0.67$ AGFI $=0.60, \mathrm{CFI}=0.93, \mathrm{RMR}=0.017$, (AIC hypothesis model $=1036.31)<($ AIC independent model $=12769.761)$.

The chi-square degree of freedom ratio is significantly affected by the number of variables and samples. This value is greater than the standard value, but the $p$ value is 0.000 , indicating that there is a significant difference between the data Although GFI and AGFI indicators were not ideal, CFI, RMR and AIC were all within the standard range. The fitting degree can be considered good. Therefore, the items of the two scales need not be modified.

\section{Structural model test}

There are mediating variables. In order to test the mediating effect of innovation ability, the model is divided into two parts. Model 1 (as shown in Fig. 1): the model when the mediating variable is not added, and model 2 (as shown in Fig. 2): the model when the mediating variable is added.

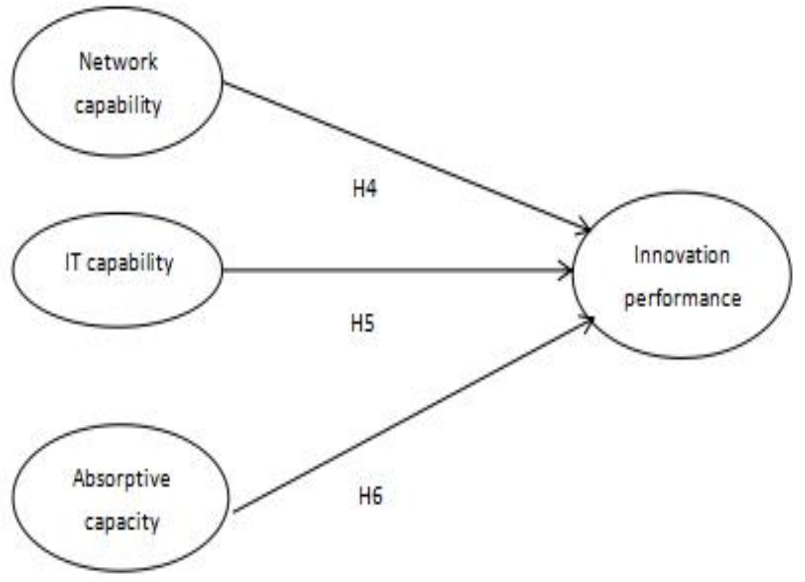

Fig. 1. Model without mediator variables

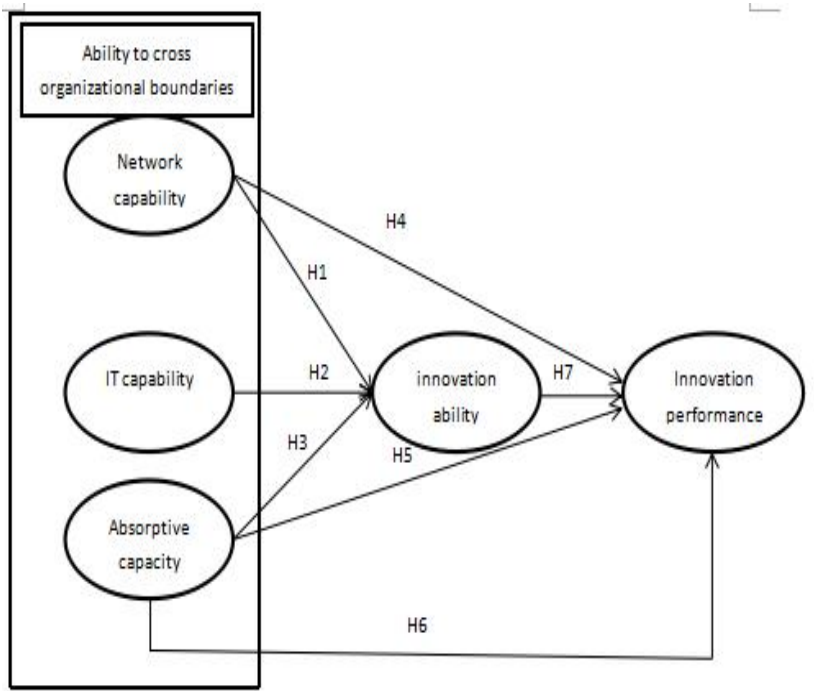

Fig. 2. Model with mediator variables

AMOS24.0 is used to estimate the parameters of the model, and the results are shown in table 1 . From table 1 , it can be seen that almost all the matching indicators of the model conform to the standards. And the data of model 1 and model 2 have significant difference, and the model fitting degree is good.

TABLE I. RESULTS OF ESTIMATION OF MODEL PARAMETERS

\begin{tabular}{|l|l|l|}
\hline & Model 1 & Model 2 \\
\hline CMIN/DF<5 & 3.72 & 5.94 \\
\hline P the smaller the better & 0.024 & 0.00 \\
\hline GFI (Close to 0.9) & 0.983 & 0.72 \\
\hline AGFI (Close to 0.9) & 0.916 & 0.65 \\
\hline CFI(Close to 0.9) & 0.963 & 0.93 \\
\hline RMEA $<0.05$ & 0.037 & 0.149 \\
\hline
\end{tabular}


As shown in table 2, test results accept $\mathrm{H} 1 \mathrm{H} 2 \mathrm{H} 4 \mathrm{H} 5 \mathrm{H} 6 \mathrm{H} 7$, and reject $\mathrm{H} 3$ because of $\mathrm{P}>0.01$ in $\mathrm{H} 3$

TABLE II. THE RESULTS OF HYPOTHESIS TESTING

\begin{tabular}{|c|c|c|c|c|c|c|c|}
\hline \multirow[t]{2}{*}{ Assuming } & \multirow[t]{2}{*}{ path } & \multicolumn{3}{|c|}{ Model 1} & \multicolumn{3}{|c|}{ Model 2} \\
\hline & & $\begin{array}{l}\text { Standard } \\
\text { estimate }\end{array}$ & $P$ & $\begin{array}{l}\text { Test } \\
\text { results }\end{array}$ & $\begin{array}{l}\text { Standard } \\
\text { estimate }\end{array}$ & $\mathrm{P}$ & $\begin{array}{l}\text { Test } \\
\text { results }\end{array}$ \\
\hline $\mathrm{H} 1$ & $\begin{array}{c}\text { Network } \\
\text { capability } \\
\cdots>\text { innovation } \\
\text { ability }\end{array}$ & קי- & -...... & 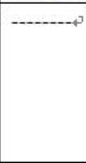 & 27.86 & $* * *$ & accept \\
\hline $\mathrm{H} 2$ & $\begin{array}{c}\text { IT } \\
\text { capability } \cdots> \\
\text { innovation } \\
\text { ability }\end{array}$ & 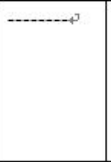 & $\ldots$ & 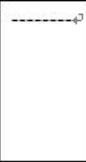 & 18.58 & $* * *$ & accept \\
\hline $\mathrm{H} 3$ & $\begin{array}{c}\text { Absorptive } \\
\text { capacity } \\
\cdots>\text { innovation } \\
\text { ability }\end{array}$ & ני-n & $\ldots$ & 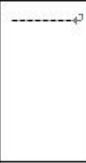 & 0.75 & 0.279 & $\begin{array}{l}\text { Not } \\
\text { accept }\end{array}$ \\
\hline $\mathrm{H} 4$ & $\begin{array}{c}\text { Network } \\
\text { capability } \\
\cdots>\text { Innovation } \\
\text { performance }\end{array}$ & 28.41 & $* * *$ & accept & 2.45 & $* * *$ & accept \\
\hline $\mathrm{H} 5$ & $\begin{array}{c}\text { IT } \\
\text { capability } \cdots> \\
\text { Innovation } \\
\text { performance }\end{array}$ & 17.05 & $* * *$ & accept & 2.09 & $* * *$ & accept \\
\hline $\mathrm{H} 6$ & $\begin{array}{c}\text { Absorptive } \\
\text { capacity } \\
\cdots>\text { Innovation } \\
\text { performance }\end{array}$ & 0.72 & $* * *$ & accept & 0.02 & $* * *$ & accept \\
\hline $\mathrm{H} 7$ & $\begin{array}{c}\text { innovation } \\
\text { ability } \cdots> \\
\text { Innovation } \\
\text { performance }\end{array}$ & p.m & - & 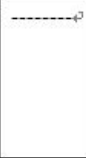 & 0.22 & $* *$ & accept \\
\hline
\end{tabular}

\section{Mediating effect analysis}

Compared with model 1 , the standard estimate of the impact of network capability on innovation performance changed from 28.41 to 2.45 , but $\mathrm{P}<0.001$. However, the standard estimate of the impact of network capability on innovation capability changed to 27.86 and $\mathrm{P}<0.001$, indicating that innovation capability played a partial intermediary role. The standard estimation value of It capability for innovation performance changes from 17.05 to 2.09 and $\mathrm{p}<0.001$, and the standard estimation value of It capability for innovation performance is 18.58 and $\mathrm{p}<0.001$, indicating that innovation capability has a partial intermediary effect between It capability and innovation performance. The effect of absorptive capacity on innovation capability is more than 0.01 , and there is no intermediary effect between absorptive capacity and innovation performance.

\section{E. model effect analysis}

The direct and indirect effects between variables are shown in table 3 and Fig. 3 below
TABLE III. THE RESULT OF MODEL EFFECT ANALYSIS

\begin{tabular}{|c|l|l|l|}
\hline path & Direct effect & indirect effect & Total effect \\
\hline $\begin{array}{c}\text { Network capability } \\
\cdots>\text { innovation ability }\end{array}$ & 0.472 & 0 & 0.472 \\
\hline $\begin{array}{r}\text { IT capability } \cdots>\text { innovation } \\
\text { ability }\end{array}$ & 0.303 & 0 & 0.303 \\
\hline $\begin{array}{c}\text { Absorptive capacity } \\
\cdots>\text { innovation ability }\end{array}$ & 0.075 & 0 & 0.075 \\
$\begin{array}{c}\text { Network capability } \\
\cdots>\text { Innovation performance+ }\end{array}$ & 0.803 & 0.007 & 0.820 \\
\hline $\begin{array}{c}\text { IT capability } \cdots>\text { Innovation } \\
\text { performance }\end{array}$ & 0.360 & 0.009 & 0.369 \\
\hline $\begin{array}{c}\text { Absorptive capacity } \\
\cdots>\text { Innovation performance+ }\end{array}$ & 0.422 & 0.003 & \\
\hline $\begin{array}{c}\text { innovation ability } \cdots> \\
\text { Innovation performance }\end{array}$ & 0.034 & 0 & 0.425 \\
\hline$\quad$
\end{tabular}

Network capability and IT capability have a direct and significant impact on innovation capability, with a direct effect of 0.472 and 0.303 , respectively, while the absorption capacity has a relatively weak direct effect on innovation capability, with a direct effect of 0.075 . The direct impact of innovation capability on innovation performance is 0.034 , which has a significant impact. In the model, innovation capability not only plays a mediating influence, but also a direct cause of influencing innovation performance. The direct impact of network capability on innovation performance is 0.803 , the indirect effect is $0.206 \times 0.034=0.007$, the direct effect of IT capability on innovation performance is 0.36 , and the indirect effect is $0.265 \times 0.034=0.009$. The indirect effect is much smaller than the direct effect. For leaders, improving network and IT capabilities can immediately improve innovation performance. This is partly because innovation is hard to quantify and perceive.

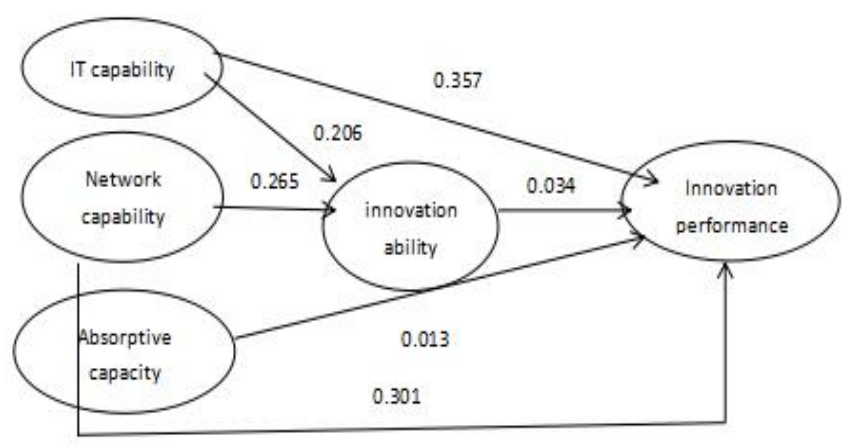

Fig. 3. Effect analysis results of the model

\section{CONCLUSIONS AND LIMITATIONS}

\section{A. Conclusions}

In this paper, 223 valid questionnaires were collected, and the results showed that IT ability and network ability had positive effects on innovation ability and innovation performance, while absorption ability only had positive effects on innovation performance, but had no significant effects on 
innovation ability. Among them, innovation ability, as a mediating variable, plays a partial mediating role in the impact between IT ability, network ability and innovation performance

\section{B. limitations}

The questionnaire sample is small, which is 223 valid samples. and there are fewer middle and senior managers, which have a weak perception of innovation performance and may weaken the mediating influence of innovation ability. The sample areas and industries are relatively dispersed, making the conclusions more general and not targeted.

\section{REFERENCES}

[1] LIU Pengcheng, SUN Xinbo, ZHANG Dapeng, WEI Xiaolin, "Study on the Impact of Organizational Boundaries Spanning Competence on the Open Service Innovation," [J] Science of Science and Management of S.\& T., 2016, 37(11) : 136- 151. In Chinese

[2] Bruce Kogut, Udo Zander, "Knowledge of the Firm, Combinative Capabilities, and the Replication of Technology," [J] Organization Science, 1992, 3(3) : 383- 397.

[3] LIU Yang, WEI Jiang, JIANG Shisong, "How Do the Latecomer Firms Catch up in Innovation?A Study from the Perspective of the Boundary Expanding in R\&D?" [J] Management World, 2013, 3: 96- 110. In Chinese

[4] AndersenPH, Kragh H, LettlC, "Spanning Organizational Boundaries to Manage Creative Processes: the Case of the LEGO Group," [J] Industrial Marketing Management, 2013, 42(1) : 125 -134

[5] ZHONG Jing, Wu Sizong, ZHANG Bo, "A Case Study of High-tech Firms' Learning beyond Boundaries" [J] Studies in Science of Science, 2008, 26(3): 578- 583. In Chinese

[6] OUYANG Taohua, DING Ling, GUO Ruijie, "Co-evolution of Boundary Spanning and IT Capability: Case Study on Haier's Information System," [J] China Industrial Economics, 2012, 12: 128140. In Chinese

[7] ZHOU Shengqiang, "Re-recognition of Firm Boundaries of the Internet Age - Based on A Knowledge-based Theory of the Firm," [J] Forward Position or Economics, 2017, 5(3) : 71- 80. In Chinese

[8] LI Yichao, DAI Guilin, "Evaluation of Enterprise Performance Improvement Based on Network Capability," Statistics \& Decision, 2018, (10) : 186-188. In Chinese

[9] CHANG Xiyin, SUN Yuchun, "Interaction Analysis and Countermeasure Research on Collaborative Innovation Capability and Knowledge Diffusion*_ Based on the Perspective of Network Embedding," Shanghai Economic Research, 2018, (5): 34- 41. In Chinese
[10] SHAO Yunfei, PANG Bo, FANG Jiaming, "Research on Multi-factor Synergy and Innovation Performance within Enterprises from the Perspective of IT Capability," Management Review, 2018, (6) : 70- 80. In Chinese

[11] ZHENG Wansong, SUN Xiaolin, WANG Kanliang, "Research on the Relationship among IT Capability, Knowledge Sharing, Service Innovation Capability and Quality," Decision Reference, 2014, (11) : 62- 64. In Chinese

[12] CHEN Sheng, LIU Ze, ZHANG Nan, "Empirical Study on Influence of Enterprise Information on Innovation Capability in Resource-oriented Regions - Based on Resource View Theory," Soft Science, 2017, (11) : 44- 48. In Chinese

[13] SUN Qian, OU Guangjun, "Double Network Embeddedness and Enterprise Innovation Performance - A Mechanism Study Based on Absorptive Capacity," Scientific Research Management, 2018, (5) : 6776. In Chinese

[14] ZHANG Peng, "Research on the Promotion of Enterprise Innovation Ability under the Background of Big Data: Based on the Perspective of Knowledge Absorption Ability," Shandong Social Sciences, 2018, (3) : 130- 135. In Chinese

[15] ZHANG Baojian, SUN Guoqiang, "Network Capability, Network Structure and Entrepreneurial Performance - An Empirical Study Based on China's Incubation Industry," [J] Nankai Business Review, 2015, 18(2) : 39- 50. In Chinese

[16] CHEN Xueguang, "Research on the Relationship among Network Capability, Innovation Network and Innovation Performance- Taking Zhejiang High and New Technology Enterprises as An Example," [D] Zhejiang University, 2007, 9. In Chinese

[17] Jensen M B, Johnson B, Lorenz E, Lundvall B A, Forms of Knowledge and Modes of Innovation[J], Research Policy, 2007, 36(5):680-693

[18] WANG Lei, "Research on the Relationship between the Potential Knowledge Absorption Ability and the Realization of Knowledge Absorption Ability of Small and Medium-sized Science and Technology Enterprises and Their Innovation Performance," [D] Hunan University, 2011, 10(8). In Chinese

[19] Fabrizio K R, “Absorptive Capacity and Innovation: Evidence from Pharmaceutical and Biotechnology Firms," [J] Research Policy, 2009, 38(2) : 255-267. In Chinese

[20] ZHANG Deming, Li Yan, "Research on the Relationship between the Potential Knowledge Absorption Ability and the Realization of Knowledge Absorption Ability of Small and Medium-sized Science and Technology Enterprises and Their Innovation Performance, 2011, 23(6) 56- 67. In Chinese

[21] LI Zhengfeng, YE Jinfu, CAI Jianfeng, "Study on the Relationships among IT Resources, IT Capabilities and Enterprises' Sustainable Competitive Advantage," [J] Science of Science and Management of S\&T, 2011, 32(4) : 147- 151. In Chinese 